\title{
Case Report When the Patient Believes That the Organs Are Destroyed: Manifestation of Cotard's Syndrome
}

\author{
Leonardo Machado, ${ }^{1}$ Luiz Evandro de Lima Filho, ${ }^{2}$ and Liliane Machado ${ }^{3}$ \\ ${ }^{1}$ Neuropsychiatry Department and Postgraduation in Neuropsychiatry and Behavior Sciences Program, \\ The Federal University of Pernambuco, 50670-901 Recife, PE, Brazil \\ ${ }^{2}$ Psychology Department, The ESUDA College, 50050-100 Recife, PE, Brazil \\ ${ }^{3}$ Hospital of Mental Health Professor Frota Pinto, 60841-110 Fortaleza, CE, Brazil \\ Correspondence should be addressed to Leonardo Machado; leonardo.machadot@ufpe.br
}

Received 31 July 2016; Accepted 7 November 2016

Academic Editor: Hitoshi Okamura

Copyright ( $\odot 2016$ Leonardo Machado et al. This is an open access article distributed under the Creative Commons Attribution License, which permits unrestricted use, distribution, and reproduction in any medium, provided the original work is properly cited.

Cotard's Syndrome (CS) is a rare clinical event described for the first time in 1880 by the neurologist and psychiatrist Jules Cotard and characterized by negation delusions (or nihilists). Immortality and hypochondriac delusions are also typical. Nowadays, it is known that CS can be associated with many neuropsychiatric conditions. In this article, we describe the case of a patient that believed not having more organs and having the body deformed and whose CS was associated with a bigger depressive disorder. Although the electroconvulsive therapy is the most described treatment modality in the literature, the reported case had therapeutic success with association of imipramine and risperidone.

\section{Introduction}

Cotard's Syndrome (CS) is a rare clinical event, characterized by negation delusion (or nihilist), generally regarding the body (frequently the patient believes that he or she does not have one or more organs) or regarding the existence (the individual judges that himself or everybody in the world is dead or reduced to nothing, being able to judge himself a zombie), but also concerning concepts/conditions [1] (such as a CS case described in which a woman was sure about not being pregnant, despite of obvious evidences [2]). Besides that, other typical delusions are immortality delusion (the individual believes that nothing more can kill him, in this case because he is already dead) [3] and hypochondriac delusions (in which the patient judges to be suffering of a very serious or incurable disease or having the body deformed) $[1,4]$.

This condition was described with details in 1880 by the Parisian neurologist and psychiatrist Jules Cotard [5]. He described the clinical condition of a 43-year-old woman who affirms not to have many organs, but only a body in decomposition. Initially, Cotard formulated that the condition would be a new kind of depression characterized by anxious melancholy, condemnation of ideas, insensitivity to pain, negation delusion of the organs, and immortality delusion. Sometime later, he created the term negation delusion to denominate the syndrome $[6,7]$.

Nowadays, it is known that this syndrome may be secondary to many conditions such as psychotic depression [811], schizophrenia [3], bipolar disorder [12, 13], dementia [14], cerebral neoplasm [15], cerebral hemorrhage [16], and use of psychoactive substances [17], among other neuropsychiatric conditions. Besides that, associations of CS with other syndromes are described, such as catatonic syndrome [18], malignant neuroleptic syndrome [19], lycanthropy [20], hydrophobia [21], and capgras syndrome [22, 23].

Although rare, CS involves big suicide risk and, because of that, it is recommended to institute treatment as early as possible [7]. Thus, it is necessary that the clinicians be aware to the many possibilities of manifestation of this syndrome and, because of that, we describe in this article a CS case with negation delusions of organs and hypochondriac. 


\section{Case Presentation}

Patient, a 31-year-old male, was examined in the Sector of Psychiatric Emergency of a Psychiatric Hospital of Brazil presenting insomnia, feed refusing, soliloquies, and hanging suicide attempt. He suspended his previous psychiatric medicines by himself. There were no other clinical changes. At the mental exam, he presented poor hygiene, disheveled hair, unshaven, and passive posture, he was self-referential, alert, with hypoprosexia, oriented, he had seriously depressed humor, intense psychomotor retardment, and very slowly thinking and with many blocks. He reported that his organs were destroyed, that he was hollow inside, and that he was a rotten and smelly flesh (negation delusion regarding the body, including the organs). He referred that his body was deformed and that his face was full of holes (hypochondriac delusion), including trying to show to the examiner doctor. He referred will to die. He said that he was paying for what he had done wrong in the past (guilty delusion) and that he was not worthy feeling happiness, besides to be sure that he would never see the sun light again (condemnation delusion). The patient was hospitalized. It was diagnosed CS secondary to serious depressive disorder with psychotic symptoms. As the service did not dispose of an electroconvulsive therapy machine, he was prescribed imipramine $150 \mathrm{mg} /$ day associated with risperidone $6 \mathrm{mg} /$ day. The patient was released from the hospital, about 60 days later, asymptomatic.

\section{Discussion}

We described a CS case secondary to a serious depression with psychotic symptoms. The main delusion involved in the syndrome, the negation one, stands out in the condition. Besides it, hypochondriac delusion as the way described by Cotard (an interpretation of pathological sensations) [1] was present, as well as guilty and condemnation delusions congruent with the depressed humor. Among 100 cases described in the literature analyzed by Berrios and Luque [1], 89 had depressed humor and the most commonly found delusion was the nihilist related to the body ( 86 cases). Besides this delusion, another characteristic of CS that was reported in our case, the hypochondriac, was present in 58 patients. The delusions that are common in CS and were present in our report, despite not defining a syndrome, were found in 63 reports (guilty delusion) and in 35 (condemnation delusion).

CS is a rare condition; therefore it is not clear which treatment should be considered as the first choice. The electroconvulsive therapy (ECT) has been the preferred treatment form for CS in several case reports $[7,10,14,19]$. This preference is possibly justified by the fact that CS is a serious psychotic syndrome, generally associated with an equally serious humor situation and with high suicide risk. However, especially in Brazil, the ECT is not always an easy availability option because its use is not financed by the public service and the stigma is still an important limiting factor. The medication treatment is also described as successful [2, 3, 8, 11, 18, 22] and, in these cases, frequently with preference for using antipsychotics in association with antidepressants $[8,11]$ as exemplified in this report. Anyway, the treatment should be directed to the basis cause.

In 1968, Saavedra classified CS as genuine CS, which occurred only in depressive states, and the pseudo-CS [7]. However, it was only in 1995 that appeared a classification based on evidence. Through retrospective analysis of 100 case reports in the literature, Berrios and Luque [1] subdivided the syndrome into three subtypes. The first type, denominated psychotic depression, includes patients with melancholia and few nihilist delusions. The second, called CS type I, includes conditions that course with nihilist and hypochondriac delusions in absence of humor changes. And the third, denominated CS type II, includes heterogeneous conditions which course with anxiety, depression, immortality delusion, nihilist delusion, and/or auditory hallucination. Nowadays, CS is not classified as an isolated disorder in the 5th edition of Diagnostic and Statistic Manual of Mental Disorders (DSM5) neither in the International Classification of Diseases (ICD-10). At DSM-5, nihilist delusion is classified as delusion congruent with the humor inserted in a grave depressive episode with psychotic symptoms $[24,25]$. Our report can be classified as genuine CS, once it is associated with a depressive disorder, as well as CS type II for presenting depression and nihilist delusion. At DSM-5, however, it would be classified only as a more severe depressive disorder with psychotic characteristics congruent with the humor.

From the neurobiological point of view, there are some reports with PET scan studies which suggest a hypometabolism of the frontal-parietal-temporal cortex associative circuit $[6,26,27]$ and a hypermetabolism in the basal ganglia $[26,27]$ and cerebellum [26]. However, it was not possible to proceed neuroimaging studies for the reported patient due to the lack of availability of these examinations in our region through the public health system.

\section{Conclusion}

Although rare and described more than 120 years ago, CS is still a present phenomenon in the psychiatric clinics all over the world with clinical characteristics similar to those initially observed by Jules Cotard. The case described here has a function of calling the clinicians' attention. Besides that, it shows that, even in places with lack of technologic resources (public hospital without neuroimaging and without ECT service), it is possible to recognize the situation by the clinical presentation and obtain therapeutic success with older psychotropic drugs.

\section{Competing Interests}

The authors declare that there is no conflict of interests regarding the publication of this paper.

\section{Acknowledgments}

The corresponding author acknowledges the received psychiatric teachings, including Cotard's Syndrome, from Dr. Suzana Azoubel and Dr. Antonio Peregrino. 


\section{References}

[1] G. E. Berrios and R. Luque, "Cotard's syndrome: analysis of 100 cases," Acta Psychiatrica Scandinavica, vol. 91, no. 3, pp. 185-188, 1995.

[2] J. E. Walloch, C. Klauwer, M. Lanczik, I. F. Brockington, and J. Kornhuber, "Delusional denial of pregnancy as a special form of Cotard's syndrome: case report and review of the literature," Psychopathology, vol. 40, no. 1, pp. 61-64, 2006.

[3] C. G. Huber and A. Agorastos, "We are all zombies anyway: aggression in cotard's syndrome," The Journal of Neuropsychiatry \& Clinical Neurosciences, vol. 24, no. 3, p. E21, 2012.

[4] E. Cheniaux Jr., Manual de Psicopatologia, Guanabara Koogan, Rio de Janeiro, Brazil, 5th edition, 2015.

[5] J. Pearn and C. Gardner-Thorpe, "Jules Cotard (1840-1889): his life and the unique syndrome which bears his name," Neurology, vol. 58, no. 9, pp. 1400-1403, 2002.

[6] H. Debruyne, M. Portzky, K. Peremans et al., "Cotard's syndrome," Mind \& Brain, The Journal of Psychiatry, vol. 2, no. 1, pp. 67-72, 2011.

[7] H. Debruyne, M. Portzky, F. Van den Eynde, and K. Audenaert, "Cotard's syndrome: a review," Current Psychiatry Reports, vol. 11, no. 3, pp. 197-202, 2009.

[8] L. Machado, A. Peregrino, S. Azoubel, H. Cerqueira, and L. E. de Lima Filho, "Cotard's syndrome and major depression with psychotic symptoms," Revista Brasileira de Psiquiatria, vol. 35, no. 2, p. 212, 2013.

[9] F. Mughal and S. B. Menezes, "Severe depression with Cotard's phenomenon: treatment of a capacitated patient within the United Kingdom's mental health act 2007," Mental Illness, vol. 5, no. 1, article e3, pp. 5-6, 2013.

[10] L. Machado and L. Machado, "Síndrome de Cotard: a doença da imortalidade," Revista debates em Psiquiatria, vol. 4, no. 3, pp. 34-37, 2015.

[11] D. De Berardis, M. Brucchi, N. Serroni et al., "Cotard's syndrome after breast surgery successfully treated with aripiprazole augmentation of escitalopram: a case report," Rivista di Psichiatria, vol. 50, no. 2, pp. 95-98, 2015.

[12] C. Soultanian, D. Perisse, A. Révah-Levy, R. Luque, P. Mazet, and D. Cohen, "Cotard's syndrome in adolescents and young adults: a possible onset of bipolar disorder requiring a mood stabilizer?" Journal of Child and Adolescent Psychopharmacology, vol. 15, no. 4, pp. 706-711, 2005.

[13] A. Consoli, C. Soultanian, M.-L. Tanguy et al., "Cotard's syndrome in adolescents and young adults is associated with an increased risk of bipolar disorder," Bipolar Disorders, vol. 9, no. 6, pp. 665-668, 2007.

[14] T. Kobayashi, K. Inoue, K. Shioda, and S. Kato, "Effectiveness of electroconvulsive therapy for depression and Cotard's syndrome in a patient with frontotemporal lobe dementia," Case Reports in Psychiatry, vol. 2012, Article ID 627460, 4 pages, 2012.

[15] M. Reich, B. Comet, E. Le Rhun, and C. Ramirez, "Cotard's syndrome with glioblastoma multiforme," Palliative \& Supportive Care, vol. 10, no. 2, pp. 135-139, 2012.

[16] D. L. Perez, B. H. Fuchs, and J. Epstein, "A case of cotard syndrome in a woman with a right subdural hemorrhage," The Journal of Neuropsychiatry \& Clinical Neurosciences, vol. 26, no. 1, pp. E29-E30, 2014.

[17] R. Nicolato, J. Pacheco, L. Boson et al., "Síndrome de Cotard associada ao uso de ecstasy," Jornal Brasileiro de Psiquiatria, vol. 56, no. 1, pp. 64-66, 2007.
[18] P. Simpson, E. Kaul, and D. Quinn, “Cotard's syndrome with catatonia: a case presentation and discussion," Psychosomatics, vol. 54, no. 2, pp. 196-199, 2013.

[19] C. Weiss, J. Santander, and R. Torres, "Catatonia, neuroleptic malignant syndrome, and cotard syndrome in a 22-year-old woman: a case report," Case Reports in Psychiatry, vol. 2013, Article ID 452646, 3 pages, 2013.

[20] A. G. Nejad and K. Toofani, "Co-existence of lycanthropy and Cotard's syndrome in a single case," Acta Psychiatrica Scandinavica, vol. 111, no. 3, pp. 250-252, 2005.

[21] A. G. Nejad, "Hydrophobia as a rare presentation of Cotard's syndrome: a case report," Acta Psychiatrica Scandinavica, vol. 106, no. 2, pp. 156-158, 2002.

[22] P. V. Butler, "Diurnal variation in Cotard's syndrome (copresent with Capgras delusion) following traumatic brain injury," Australian \& New Zealand Journal of Psychiatry, vol. 34, no. 4, pp. 684-687, 2000.

[23] S. Wright, A. W. Young, and D. J. Hellawell, "Sequential Cotard and Capgras delusions," British Journal of Clinical Psychology, vol. 32, no. 3, pp. 345-349, 1993.

[24] World Health Organization, The ICD-10 Classification of Mental and Behavioural Disorders, World Health Organization, Geneva, Switzerland, 1992.

[25] American Psychiatric Association, Diagnostic and Statistical Manual of Mental Disorders, American Psychiatric Association, Washington, DC, USA, 5th edition, 2013.

[26] V. Charland-Verville, M.-A. Bruno, M. A. Bahri et al., "Brain dead yet mind alive: a positron emission tomography case study of brain metabolism in cotard's syndrome," Cortex, vol. 49, no. 7, pp. 1997-1999, 2013.

[27] N. Ozkan and O. Caliyurt, "Brain metabolism changes with 18 F-fluorodeoxy- glucose-positron emission tomography in a patient with Cotards syndrome," Australian \& New Zealand Journal of Psychiatry, vol. 50, no. 6, pp. 600-601, 2016. 


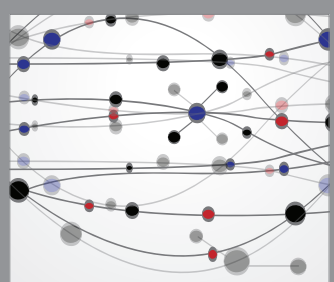

The Scientific World Journal
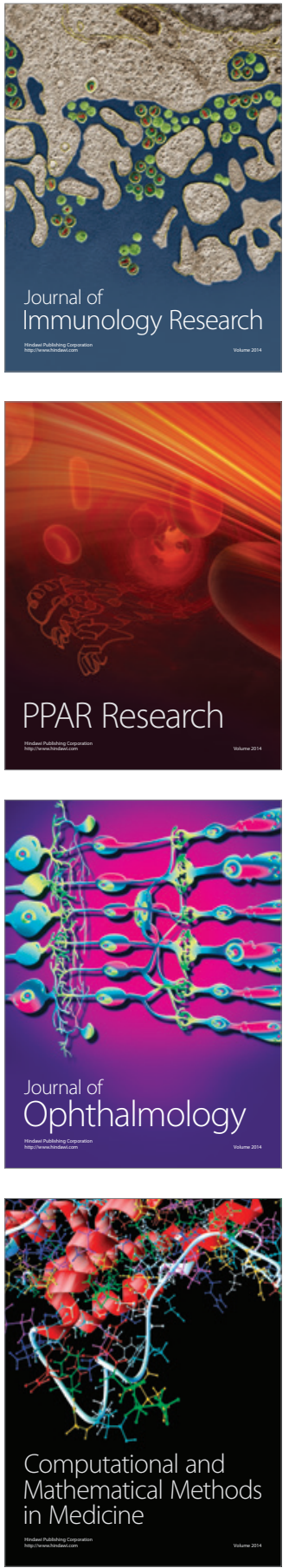

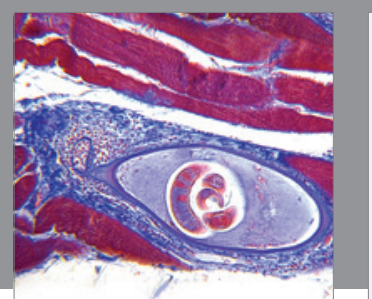

Gastroenterology Research and Practice

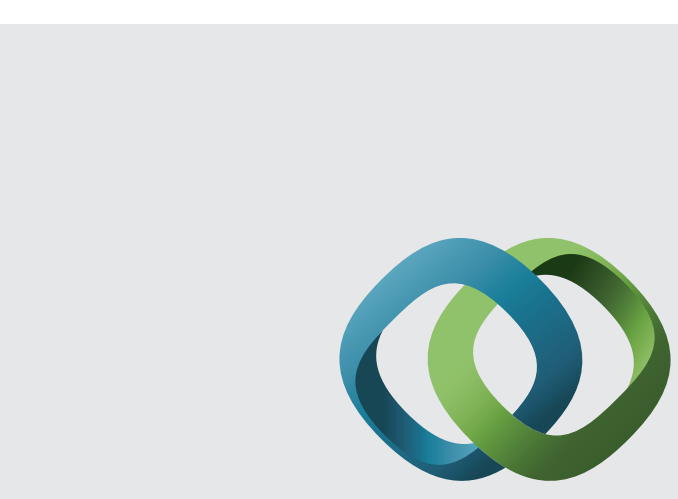

\section{Hindawi}

Submit your manuscripts at

http://www.hindawi.com
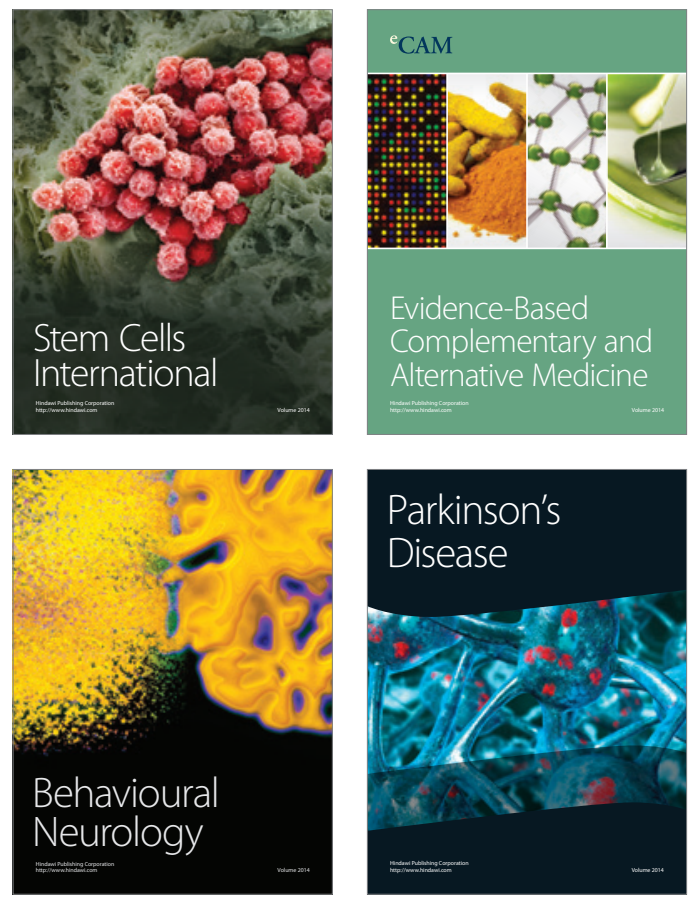
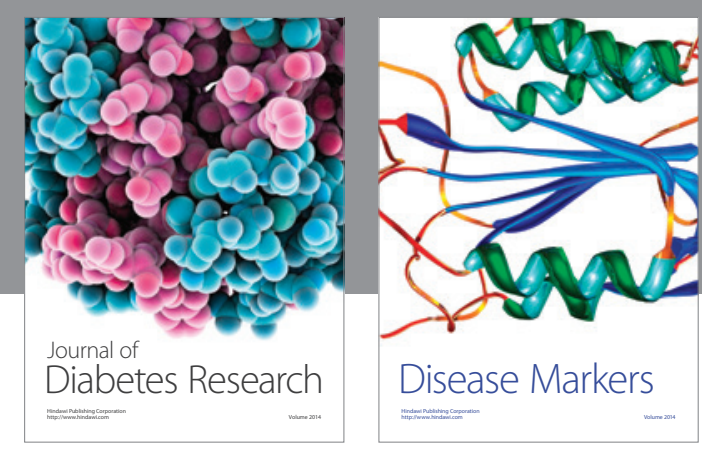

Disease Markers
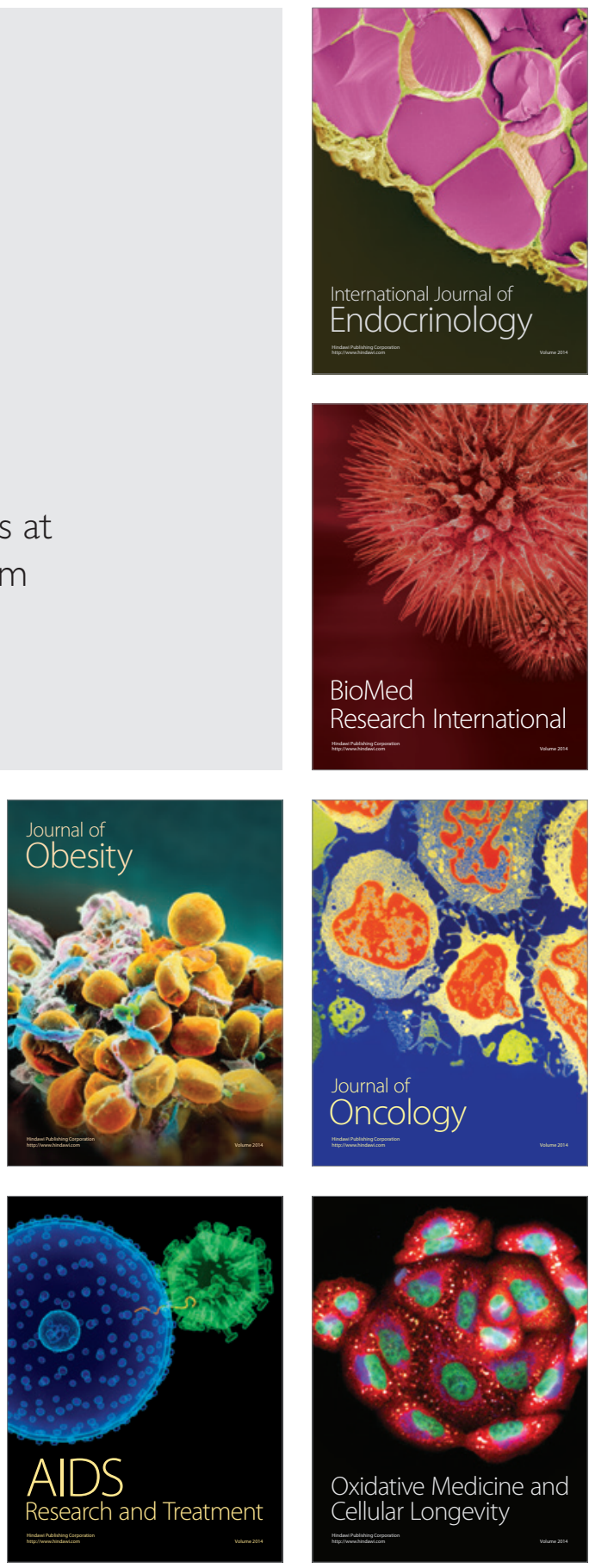